\title{
Interview
}

\section{Early work on the function of Bcl-2, an interview with David Vaux}

\author{
DL Vaux ${ }^{*, 1}$ \\ 1 The Walter and Eliza Hall Institute, 1G Royal Parade Parkville, Victoria, Australia \\ * Corresponding author: DL Vaux, The Walter and Eliza Hall Institute, 1G Royal Parade Parkville, Victoria 3050, Australia. E-mail: vaux@ wehi.edu.au
}

Cell Death and Differentiation (2004) 11, S28-S32. doi:10.1038/sj.cdd.4401439

Published online 30 April 2004

This interview is part of a series of articles to mark the 10th anniversary of Cell Death and Differentiation.

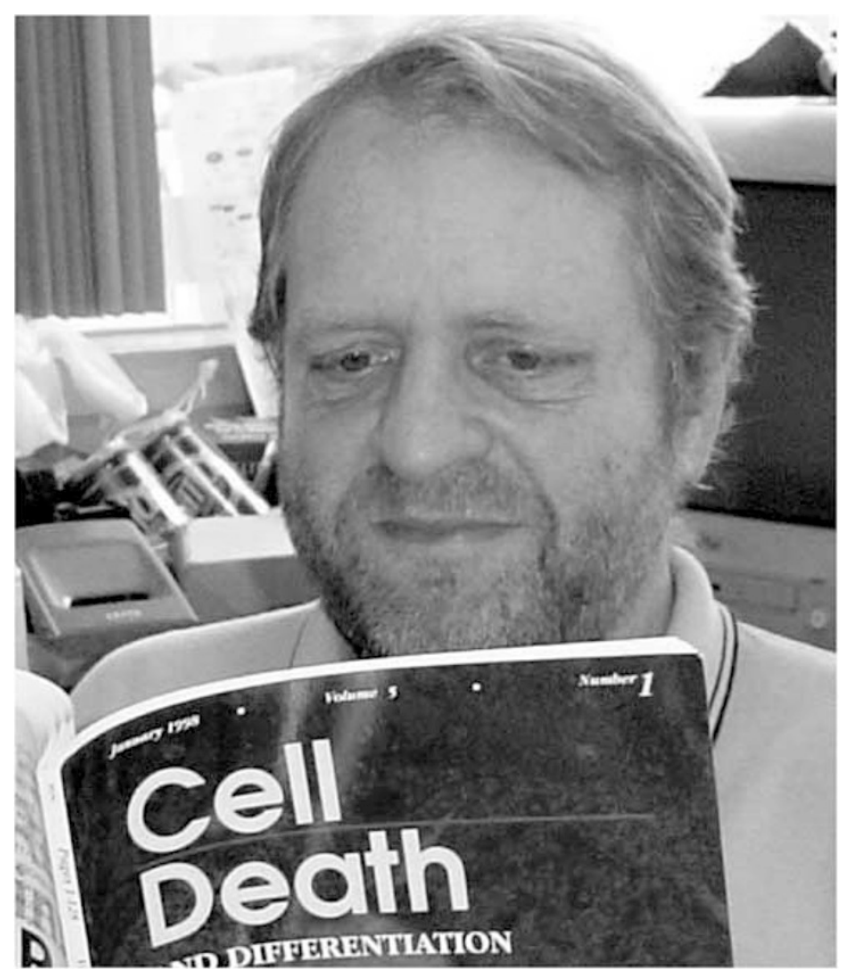

David Vaux graduated in medicine from Melbourne University in 1984. After interning at The Royal Melbourne Hospital, he commenced a PhD at The Walter and Eliza Hall Institute in 1986. He was a Lucille P. Markey Fellow at Stanford from 1989 to 1993, when he returned to The Walter and Eliza Hall Institute.

$\mathrm{Bcl}-2$ was the first component of the apoptotic mechanism to be molecularly characterized in any organism. Expression of $b c l-2$ in growth factor-dependent cell lines showed that it could prevent activation of a default death process when factor was removed, and revealed that cell growth and cell survival were under independent genetic control. Expression of human bcl-2 in Caenorhabditis elegans showed that programmed cell death and apoptosis were the same mechanism that had be conserved for a billion years, and demonstrated that genetic analysis of cell death in the worm had relevance to human diseases such as cancer. Here, Cell Death and Differentiation asks David Vaux about the early work on Bcl-2.

\section{CDD: How was Bcl-2 first identified?}

The $b c l-2$ gene was first identified by Yoshide Tsujimoto in Carlo Croce's lab ${ }^{1}$ at the site of translocations characteristic of follicular lymphoma, the most common cancer of blood cells in humans. Croce was systematically identifiying the genes at the breakpoints of translocations in B-cell lymphomas, and naming them 'Bcl-1', 'Bcl-2', 'Bcl-3', etc. for B-cell leukemia/ lymphoma gene number 1, 2, 3, and so on.

The strong association of the $\mathrm{t} 14: 18$ translocation with follicular lymphoma suggested that $b c /-2$ might be an oncogene, perhaps like $a b l$, which is involved in the translocations that generate the Philadelphia chromosome in chronic myeloid leukemia, or $c-m y c$, which is involved in the t8:14 translocations of Burkitt's lymphoma. Following cloning of the breakpoint, the full-length $b c l-2$ cDNA was cloned in 1986 by both Tsujimoto in Philidelphia ${ }^{2}$ and Mike Cleary at Stanford. ${ }^{3}$

\section{CDD: When did you first hear about Bcl-2?}

On January 15th 1987, my PhD supervisor Jerry Adams received the $b c l-2$ cDNA that had kindly been sent by Mike Cleary. In the accompanying letter, Mike wrote that he would be happy for us to use the cDNA anyway we wished, but he asked us not to make transgenic mice because that was an experiment he planned to carry out. My task was therefore to figure out whether $b c l-2$ was an oncogene whose overexpression was responsible for causing follicular lymphoma.

\section{CDD: What were your first experiments with $b c /-2$ ?}

I thought l'd look to see if it could act like other oncogenes to transform fibroblasts, as had been shown for ras, ${ }^{4} v$-raf $f^{5}$ and 
SV40 large $\mathrm{T},{ }^{6}$ or make growth factor-dependent cells factor independent, as had been shown for $v$-abl and $v$-fms. ${ }^{8}$

To express the $b c l-2$ cDNA, I took advantage of a retroviral vector called MPZen designed by Iswar Hariharan, another student in the lab, ${ }^{9}$ as I had been using this vector to express IL-5 in both factor-dependent FDC-P1 cells ${ }^{10}$ and primary bone marrow cells. ${ }^{11}$ Since neither the $\psi 2$ retrovirus packaging cells, nor NIH 3T3 fibroblasts, expressing bcl-2 from the retroviral construct became morphologically transformed, ${ }^{12}$ it did not take long to be convinced that $b c l-2$ was not a transforming oncogene like mutated ras or $v$-raf.

\section{CDD: So it did not transform fibroblasts, but what about the growth factor-dependent cells?}

The retrovirus was used to infect the myeloid cell line FDC-P1 and the prolymphoid line $\mathrm{LyH} 7^{13}$ to see if $\mathrm{Bcl}-2$ could make cells grow, as these lines were both dependent on the growth factor IL-3. Initially, I was disappointed to find that no colonies grew when multiple clones of cells infected with the $b c l-2$ virus were plated in soft agar in the absence of IL-3. Furthermore, when Bcl-2-expressing FDC-P1 cells were injected into syngeneic mice, no tumors grew, and when the $b c l-2$ retrovirus was used to infect bone marrow cells for reconstitution of lethally irradiated mice, the mice did not develop lymphoma. ${ }^{12}$ Clearly, $b c /-2$ did not have oncogenictransforming and growth-stimulatory activities like $v$-ablor $v$-raf.

When counting the cells in liquid culture after growth factor withdrawal, and when examining the soft agar plates for colonies, there was however one clear difference between the bcl-2 and control virus-transfected cells. While only dead cells could be seen in the soft agar in the control plates, in the plates of bcl-2-expressing cells, individual cells and pairs of cells could be seen that still looked healthy several days after plating in growth factor-free media. Although I was disappointed that the pairs of cells that were generated by one division never went on to generate a colony of cells in the absence of IL-3, it was strong evidence that $\mathrm{Bcl}-2$ was doing something. In liquid culture the $b c /$-2-expressing cells failed to proliferate when IL-3 was removed, but neither did they die like the control cells, they just sat, looking shrunken but otherwise healthy, at the bottom of the well.

\section{CDD: What did this mean?}

When cells die following removal of a growth factor, they do not die through lack of nutrients, oxygen or energy substrate. They die because they lack a signal from the growth factor receptors, rather than because they are starved or injured. Their death is not directly due to an outside insult, it is really a decision by the cell to kill itself when it receives (or fails to receive) certain information. $\mathrm{Bcl}-2$ therefore did not appear to act by providing a growth signal or a nutrient, it was somehow stopping a cell from activating a default suicide process. ${ }^{12}$

The proof that $\mathrm{Bcl}-2$ was preventing cell death, and not just delaying it or making dead cells exhibit a different appearance, came by adding back IL-3 to the factor-deprived cells. After a short delay, the bcl-2-transfected cells began to proliferate and formed colonies in soft agar. From these experiments it was apparent that Bcl-2 does not affect whether cells grow or divide, it acts purely to prevent cells from committing suicide.

\section{CDD: Does Bcl-2 influence cell growth or division?}

These experiments showed that cell growth and cell survival were independent processes under separate genetic control. Since a growth factor could stimulate growth and proliferation as well as inhibiting a default suicide pathway, signals from the growth factor receptors must divide into two pathways, one to inhibit a death process that could also be inhibited by Bcl-2, and the other that stimulated growth and division and was not affected by Bcl-2.

\section{CDD: How did these results fit in with what was known at the time about apoptosis?}

In our paper ${ }^{12}$ we did not mention either of the terms 'apoptosis' or 'programmed cell death'. We could see that Bcl-2 was allowing cell survival by preventing activation of a physiological death process that is otherwise activated by default when growth factor is removed from factor-dependent cells. At the time I was aware of Bob Horvitz's work on programmed cell death in $C$. elegans, ${ }^{14}$ but did not know about John Kerr's work on apoptosis ${ }^{15}$ until after our paper was published. I then came across the term 'apoptosis' more and more frequently, usually in relation to the observation of DNA laddering following some stimulus or another. This prompted me to look at the DNA of FDC-P1 cells when IL-3 was removed. I found that this generated beautiful ladders, whereas the DNA of living cells (either those cultured with IL-3 or because of transfection with $\mathrm{Bcl}-2$ ) was intact. I also found that treating the cells with a variety of drugs and toxins also resulted in DNA laddering. At the time, Jerry and Suzanne were not interested in apoptosis or DNA laddering, so I wrote up these results as a short single author paper, saying that to unravel the mechanisms of apoptosis it would be necessary to focus on steps prior to DNA cleavage, speculating that much about the mechanisms of mammalian cell death might be learnt from studying programmed cell death in C. elegans. Unfortunately, Nature declined to publish these results as correspondence, as did Nucleic Acids Research. Eventually, I got the letter published, but without the figure, in Immunology Today. ${ }^{16}$

\section{CDD: Were there any clinical implications of this work?}

The results with retroviral expression of $\mathrm{Bcl}-2$ suggested that abnormal production of Bcl-2 in follicular lymphoma cells bearing the $\mathrm{t} 14: 18$ translocation prevented the cells from being able to kill themselves, and that inhibition of cell death could be oncogenic. ${ }^{12}$ The slow, indolent course of follicular lymphoma was consistent with an oncogene that did not cause marked transformation or stimulate rapid cell growth. 
CDD: If Bcl-2 only helps cells to survive, how does it cause cancer? Why did you look at Bcl-2 and c-myc?

Although follicular lymphoma progresses only very slowly, it can suddenly change into a much more aggressive disease. In some cases, Carlo Croce had associated this change with a subsequent translocation, this time involving the $c$-myc protooncogene. ${ }^{17}$ As I had produced a $b c l-2$ virus capable of infecting bone marrow cells, Jerry Adams suggested infecting bone marrow from $\mathrm{E} \mu$-myc transgenic mice that he, Suzanne Cory and Alan Harris and their collaborators had produced previously. ${ }^{18}$ This experiment would be able to test whether $b c l-2$ and $c-m y c$ could synergise in the transformation of cells in vitro.

The results were spectacular. ${ }^{12}$ When normal bone marrow cells, or bone marrow cells from $\mathrm{E} \mu$-myc transgenic mice were plated in soft agar with serum, but lacking specific growth factors, no colonies grew. Infection of the normal bone marrow cells with the $b c l-2$ retrovirus also allowed no growth. However, when the $\mathrm{E} \mu$-myc bone marrow cells were infected with the $b c /-2$ retrovirus and transferred to soft agar, many robust colonies formed. Bulk cultures of $b c /-2$ virus-infected $\mathrm{E} \mu$-myc bone marrow cells readily yielded immortalized lines of pre-B cells, whereas cells expressing retroviral $b c /-2$ or transgenic $c-m y c$ alone, like normal marrow, did not. Furthermore, these pre-B cell lines cause lymphoma when injected into mice. $^{12}$

\section{CDD: So why did you make $\mathrm{Bcl}-2$ transgenic mice?}

The synergy between $b c /-2$ and $c-m y c$ was dramatic, but even though the results were the same in three out of three experiments using bone marrow from different mice, I was worried that the colonies that grew might have come from a preclinical lymphoma in the $\mathrm{E} \mu$-myc marrow donors. A more elegant way of demonstrating this synergy between c-myc and $\mathrm{Bcl}-2$ would be to make transgenic $b c /-2$ mice and cross them with the $\mathrm{E} \mu$-myc transgenics, and look to see whether tumor onset was accelerated.

I discussed this plan with Jerry, who agreed that making $b c /$ 2 transgenics would be worthwhile, so we called Mike Cleary to ask his permission to go ahead and make them. Mike said that to date (May 1988) he had not observed any phenotype in his transgenics, so he said it would be OK for us to make $b c l-2$ transgenics using his cDNA.

I put the bcl-2 cDNA into two vectors that Jerry had designed and Liz Webb had constructed. One had the Ig heavy chain enhancer and SV40 promoter, the other had two Ig heavy chain enhancers and an Ig promoter. While the first founder mice resulting from oocyte injections performed by Andrew Elefanty, Helen Abud and Marge Crawford bore the bcl-2transgene, they unfortunately did not express transgenic $b c l-2$ mRNA. Luckily, Sue Bath had joined the group, and thanks to her skill, we were able to generate another 25 founder lines. I analyzed these lines by Southern blot to look at the transgene integrations, and by Northern blot to look for expression of transgenic $\mathrm{Bcl}-2$, and luckily several of them did. ${ }^{19}$ The founder of the Bcl-2.22 line was born on the 25th September 1988, 4 days before our paper describing the survival properties of $\mathrm{Bcl}-2$ was published. ${ }^{12}$

\section{CDD: What other work was being carried out at the time on Bcl-2?}

In March 1989, I went to the Mechanisms of B-Cell Neoplasia workshop in Basel. There was quite a lot of discussion, much of it led by lan MacLennan, about Bcl-2 inhibiting apoptosis and whether DNA degradation was part of the cell death mechanism or occurred after the cell had committed to die. ${ }^{20}$ I talked about the effects of Bcl-2 on bone marrow and growth factor-dependent cells, ${ }^{21}$ and Stan Korsmeyer spoke about the $b c /-2$ transgenic mice made by in his lab by Tim McDonnell. ${ }^{22}$ He described how splenocytes from these mice, but not those from control littermates, survived for prolonged periods when cultured in medium with just $5 \%$ fetal calf serum, confirming Bcl-2's ability to promote survival in the absence of growth factors. Like our mice, these transgenic mice had enlarged spleens and lymphoid hyperplasia, but none had developed malignant disease. The paper describing Korsmeyer's mice was published in Cell in April 1989. ${ }^{23}$

\section{CDD: What did you do with your Bcl-2 transgenics?}

Back at WEHI, with help from Sue Bath and Alan Harris, I set up the cross between the $\mathrm{E} \mu$-myc transgenic mice and $\mathrm{Bcl}-$ 2.22 transgenics on the 5th of May 1989. I carried out autopsies of the first sick pups from this cross on the 4th of July, and Andreas Strasser, who had arrived to commence his post-doc in June, analyzed their lymphocytes by flow cytometry, and found they had pre- or pro-B-cell leukemias. ${ }^{24}$ Mice overexpressing both c-myc and $\mathrm{Bcl}-2$ developed leukemia extraordinarily rapidly.

\section{CDD: So you and Andreas only overlapped for a couple of months? What did he do with the Bcl-2 transgenics?}

In August, I left for Stanford, leaving the Bcl-2 transgenics in Andreas's most capable hands. Andreas noticed that although very few of the Bcl-2 transgenic mice developed lymphoid neoplasia, many died at a relatively early age. He thought they might be suffering from some kind of autoimmune disease, and with help from Alan Harris and Senga Wittingham proved that this was indeed the case. ${ }^{19}$ They were dying of renal failure due to a syndrome resembling systemic lupus erythematosus. This was the first experimental demonstration that inhibition of cell death could lead to the development of autoimmunity.

Andreas also continued analysis of the crossed $\mathrm{Bcl}-2$ and myc transgenic mice. He found that these double transgenic mice develop leukemia much more rapidly than either the $\mathrm{Bcl}-2$ transgenic mice or the myc transgenic mice, confirming the strong synergy that was observed between these genes in vitro. ${ }^{24}$ In fact, this paper was the first description of 
development of full malignancy in a Bcl-2 transgenic mouse, as Bcl-2 only transgenics only develop a nonmalignant lymphoid hyperplasia until they are very old.

\section{CDD: While Andreas was continuing to study the Bcl-2 transgenics at WEHI, you went to Stanford. What did you do there?}

At Stanford, I joined Irv Weissman's lab, where he had created an environment where any experiment seemed possible. As cells killed by cytotoxic $T$ cells exhibit classical apoptotic morphology, I wanted to see if $\mathrm{Bcl}-2$ could protect cells from killing by CTL. Experiments carried out with Leo Aguilar's help showed that Bcl-2 could not protect against CTL killing, indicating that there are some pathways to apoptosis that are not regulated by $\mathrm{Bcl}-2$. $^{25}$

In 1990, a paper appeared in Nature suggesting that Bcl-2 was located on the inner membrane of the mitochondria. ${ }^{26}$ Peter Murray, another expatriate Australian, was at the time working at the Whitehead Institute in Boston, and thought about looking at the mitochondrial role of $\mathrm{Bcl}-2$ in yeast. However, when he expressed Bcl-2 in yeast or looked at the Bcl-2-transfected mouse cell lines I sent him, he found by both electron and light microscopy that most of the Bcl-2 was located on the ER membranes, and what $\mathrm{Bcl}-2$ did bind to the mitochondria was on the outer membrane, rather than the inner membrane. We sent these findings to Nature, but they did not accept the paper, and by the time the reviewers at PNAS were considering it, a nice paper from Monaghan et al. appeared that also showed that Bcl-2 was not on the inner mitochondrial membrane, ${ }^{27}$ so unfortunately our paper was rejected from PNAS for lack of novelty.

\section{CDD: How was it that you started to work on the worm $C$. elegans?}

Thinking that evolution might provide some clues as to how Bcl-2 functioned, I thought l'd make a zoo blot, and probe it with the human $b c /-2$ cDNA. To get the DNA, I got tissue from mouse, Drosophila, Xenopus, herring and yeast from various labs at Stanford, and some chicken livers from Safeway in Menlo Park.

I went upstairs to Stuart Kim's lab to ask him for some worms or C. elegans DNA. Chatting with him, I lamented that I wished it were as easy to do genetics in mice as it was in the worm. I knew how Bob Horvitz at MIT had worked out that two genes, ced-3 and ced-4, were specifically required for cell death in $C$. elegans. ${ }^{14}$ Stuart had established techniques for making transgenic worms, so together we decided that that the best way to do genetics on mammalian cell death genes was to do it in $C$. elegans. He said that if I made a transgenic construct containing human $b c l-2$, he would inject it into his worms.

For injection of the $b c l-2$ construct, we decided to use ced-1 mutant worms, because cell corpses are easy to count in these worms as they are not efficiently engulfed. ${ }^{28}$ This experiment was very much a long shot, as no one had expressed a vertebrate gene in $C$. elegans before; humans and worms are separated by about a billion years of evolution; and Horvitz's ced-3 and ced-4 mutant worms only provided evidence for the existence of killer genes in the worm, whereas $\mathrm{Bcl}-2$ was a survival gene. However, we were greatly encouraged when we read that Michael Hengartner in Horvitz's lab had found evidence for a cell death inhibitory gene in the ced-9-mutant worms. ${ }^{29}$

\section{CDD: So what happened?}

The worms expressing human $b c /-2$ had only a third as many corpses as the controls. ${ }^{30}$ This meant that the human $\mathrm{Bcl}-2$ protein must be interacting with the worm's cell death mechanism. The fact that human Bcl-2 could work in a worm suggested that human $\mathrm{Bcl}-2$ can interact with whatever proteins the worm CED-9 protein interacts with. That, in turn, suggests that not only the gene but also the pathway of cell death is likely to be universal - conserved at least between worms and humans.

It demonstrated that apoptosis in mammalian cells and programmed cell death in the worm were one and the same process. It also meant that to find out how Bcl-2 worked would just mean finding the human homologues of ced-3 and ced-4.

We wrote up the results in a paper that we thought would have important implications for evolutionary biology, developmental biology, cancer research, immunology, neurobiology and the understanding of regulation of cell growth, as well as for cell death research. With great anticipation, we submitted the paper to Nature, but it came straight back, deemed not worth sending out for review. Disappointed, we reformatted the paper and sent it to Science, where it appeared in December 1992. ${ }^{30}$ After 2 years, Hengartner and Horvitz published the sequence of CED-9 revealing that CED-9 and Bcl-2 had sequence similarity, as well as similar functions. ${ }^{31}$ Michael Hengartner also extended our experiment by showing that human Bcl-2 could partially complement worms in which ced-9 was deleted.

\section{CDD: What were the wider implications for the work on Bcl-2?}

Experiments on $\mathrm{Bcl}-2$ gave the first molecular insights into the physiological death process now referred to as apoptosis or programmed cell death. As the first cloned gene to regulate apoptosis in both mammalian cells and $C$. elegans, Bcl-2 revealed that this process has been conserved over a billion years of evolution. In doing so, these experiments with $\mathrm{Bcl}-2$ showed the relevance of Horvitz's work on genes such as ced-3 and ced-4 that led to the identification of the caspases, the key effectors of cell death when human cells undergo apoptosis, as they do at the rate of about one million per second.

\section{Acknowledgements}

David Vaux is grateful to the funding bodies that supported this work, in particular the Lucille P Markey Trust and the National Health and Medical Research Council. He is indebted to many colleagues who contributed help, reagents ideas and discussions, but he would especially like to acknowledge the help, insights, and friendship of Andreas Strasser. 
1. Tsujimoto $Y$ et al. (1984) Science 226: 1097-1099

2. Tsujimoto $Y$ and Croce CM (1986) Proc. Natl. Acad. Sci. USA 83: 5214-5218

3. Cleary ML, Smith SD and Sklar J (1986) Cell 47: 19-28

4. McCoy MS et al. (1983) Nature 302: 79-81

5. Rapp UR et al. (1983) Proc. Natl. Acad. Sci. USA 80: 4218-4222

6. Todaro GJ and Green H (1966) Virology 28: 756-759

7. Cook WD et al. (1985) Cell 41: 677-683

8. Wheeler EF et al. (1987) Mol. Cell. Biol. 7: 1673-1680

9. Johnson GR et al. (1989) EMBO J. 8: 441-448

10. Dexter TM et al. (1980) J. Exp. Med. 152: 1036-1047

11. Vaux DL et al. (1990) Int. Immunol. 2: 965-971

12. Vaux DL, Cory S and Adams JM (1988) Nature 335: 440-442

13. Palacios R, Karasuyama $H$ and Rolink A (1987) EMBO J. 6: 3687-3693

14. Ellis HM and Horvitz HR (1986) Cell 44: 817-829

15. Kerr JF, Wyllie AH and Currie AR (1972) Br J Cancer 26: 239-257

16. Vaux DL (1989) Immunol. Today 10: 79

17. Gauwerky CE et al. (1988) Proc. Natl. Acad. Sci. USA 85: 8548-8552
18. Adams JM et al. (1985) Nature 318: 533-538

19. Strasser A et al. (1990) Curr. Top. Microbiol. Immunol. 166: 175-181

20. MacLennan I (1989) AIDS Lymphomas. Basel, Switzerland: Editiones Roche pp 103-114

21. Vaux DL (1989) Follicular Lymphoma.. Basel, Switzerland: Editiones Roche pp 159-166

22. Korsmeyer SJ (1989) Follicular Lymphoma. Basel, Switzerland: Editiones Roche pp 167-181

23. McDonnell TJ et al. (1989) Cell 57: 79-88

24. Strasser A et al. (1990) Nature 348: 331-333

25. Vaux DL, Aguila HL and Weissman IL (1992) Int. Immunol. 4: 821-824

26. Hockenbery D et al. (1990) Nature 348: 334-336

27. Monaghan P et al. (1992) J. Histochem. Cytochem. 40: 1819-1825

28. Ellis RE, Jacobson DM and Horvitz HR (1991) Genetics 129: 79-94

29. Hengartner MO, Ellis RE and Horvitz HR (1992) Nature 356: 494-499

30. Vaux DL, Weissman IL and Kim SK (1992) Science 258: 1955-1957

31. Hengartner MO and Horvitz HR (1994) Cell 76: 665 